\title{
Rebound Mechanism and Control of the Hard Main Roof in the Deep Mining Roadway in Huainan Mining Area
}

\author{
Denghong Chen $\mathbb{D}^{1,2}$ Chao Li, ${ }^{1,2}$ Xinzhu Hua, ${ }^{1,2}$ Xiaoyu Lu $\mathbb{D}^{1,2}$ Yongqiang Yuan, ${ }^{1,2}$ \\ and Chen $\mathbf{L i}^{1,2}$ \\ ${ }^{1}$ State Key Laboratory of Mining Response and Disaster Prevention and Control in Deep Coal Mines, \\ Anhui University of Science and Technology, Institute of Special Mining, Huainan 232001, Anhui, China \\ ${ }^{2}$ Institute of Energy, Hefei Comprehensive National Science Center, Hefei 230031, Anhui, China \\ Correspondence should be addressed to Denghong Chen; dhchen@aust.edu.cn
}

Received 16 August 2021; Accepted 17 September 2021; Published 5 October 2021

Academic Editor: Xiao Wang

Copyright $\odot 2021$ Denghong Chen et al. This is an open access article distributed under the Creative Commons Attribution License, which permits unrestricted use, distribution, and reproduction in any medium, provided the original work is properly cited.

Taking the occurrence conditions of the hard main roof in the deep 13-1 coal mining roadway in Huainan mining area as the research object, based on the mechanical parameters of the surrounding rock and the stress state of the main roof obtained by numerical simulation, a simply supported beam calculation model was established based on the damage factor $D$, main roof support reaction $R_{\mathrm{A}}, R_{\mathrm{B}}$, and critical range $C(9 \mathrm{~m})$ and $B(7 \mathrm{~m})$ at the elastoplastic junction of the solid coal side and mining face side (hereinafter referred to as "junction"). Considering that the damage area still has a large bearing capacity, the vertical stress of the main roof at the junction is $K_{1} \gamma H(0.05 \gamma h, 0.15 \gamma h$, and $0.25 \gamma h)$ and $K_{2} \gamma H(0.01 \gamma h, 0.10 \gamma h$, and $0.2 \gamma h)$. The maximum deflection is $21 \mathrm{~mm}, 324 \mathrm{~mm}$, and $627.6 \mathrm{~mm}$, respectively. According to the criterion of tensile failure, the maximum bending moment of the top beam is $209 \mathrm{mN} \cdot \mathrm{m}$ at the side of the working face $3.1 \mathrm{~m}$ away from the roadway side when $K_{1}=0.15$ and $K_{2}=0.10$, and the whole hard main roof is in tensile failure except the junction. To control the stability of the top beam and simplify the supporting reaction to limit the deformation of the slope angle, $R_{C}$ and $R_{D}$ are used to construct the statically indeterminate beam. By adding an anchor cable and advance self-moving support to the roadway side angle, the problem of difficult control of the surrounding rock with a large deformation of the side angle roof is solved, which provides a reference for roof control under similar conditions.

\section{Introduction}

With the rapid extraction of shallow coal resources, increasing coal mines enter deep mining. After entering the deep mining, problems such as strong ground pressure and large deformation of the stope and roadway surrounding rock under hard roof conditions have become increasingly prominent. Scholars have carried out a lot of research studies on the mechanism and prevention and control of such problems [1-3]. In terms of the ground pressure behavior law and control in hard roof stopes, the feasible region of the mechanical solution of the thin plate in the hard roof stope and the transformation method from the thick plate to the thin plate by using the method of thick plate mechanics were studied [4]. Aiming at the problem of rock burst in the hard roof working face, the main causes and influencing factors of rock burst are analyzed [5]. The problem of strong ground pressure in the hard roof stope was aspected from prediction, process change, or weighting step and strength control [6-10]. In terms of the mechanism and control of strong ground pressure in the deep roadway, in-depth research was carried out on the rheological and structural instability deformation characteristics of the surrounding rock of the deep roadway and the failure mechanism of the butterfly plastic zone by using experiments, similarity simulation, mechanical theoretical model, or numerical simulation [11-14]. Around improving the strength of the surrounding rock and reducing the range of the plastic zone, papers put forward control technologies from different angles such as prestressed anchor bolt, "three high" support, and grouting to increase initial and working anchoring force [15-18]. The response mechanism of microfracture evolution to macrodeformation is simulated and measured [19]. Scholars have analyzed the distribution characteristics and law of stress 
around the deep mining roadway [20-22]. The above research has well described and analyzed the deformation mechanism and control of the deep roadway, but there is little research on the deformation mechanism and control countermeasures of the deep hard roof mining roadway. This paper intends to take the difficult problem of difficult control of roadway large deformation in the mining process under the hard old roof of 13-1 coal in Huainan mining area as the starting point; based on the measured mechanical parameters of the surrounding rock and numerical simulation stress state, a simply supported beam mechanical model is constructed to deeply analyze the deformation mechanism and rebound mechanism of the roof surrounding rock of this kind of mining roadway to put forward targeted prevention and control countermeasures.

\section{Engineering Background}

In this paper, the mining roadway of three hard main roof occurrence working faces of 13-1 coal mine in Huainan mining area is selected as the research object, including the 1141 (3) working face of Dingji Coal Mine, 171301 working face of Liuzhuang Coal Mine, and 111303 working face of Kouzi East Coal Mine. The coal seam floor elevation is $-579 \sim-729 \mathrm{~m},-515.7 \mathrm{~m} \sim-681.2 \mathrm{~m}$, and $-742.5 \mathrm{~m} \sim-877.3 \mathrm{~m}$, the average coal seam dip angle is $7^{\circ} \sim 11^{\circ}$, and the average coal thickness is $4.76 \mathrm{~m}, 5.14 \mathrm{~m}$, and $4.5 \mathrm{~m}$; the immediate roof phase changes greatly, which is generally a composite roof composed of sandy, mudstone, and 13-2 coal. The main roof is sandy mudstone and fine sandstone of $2.7 \mathrm{~m}, 2.99 \mathrm{~m}$, and $5 \mathrm{~m}$, respectively. The comprehensive histogram of the top and bottom plate is shown in Figures 1(a)-1(c).

As is shown in Figure 1, there is a thick main roof in the mining roadway of coal 13-1. The immediate roof is mainly a composite roof, and the main roof is directly covered, occasionally, showing the characteristics of a hard main roof (the test results of surrounding rock mechanical parameters are shown in Figure 2. The uniaxial compressive strength of the coal 13-1 main roof is $122 \mathrm{MPa}$, and the tensile strength is about $13 \mathrm{MPa}$ ). At the same time, the support form of this kind of mining roadway mostly adopts anchor mesh cable support, and the roadway excavation shape is divided into a rectangular and straight wall arch; different design sizes $\left(12 \mathrm{~m}^{2}, 17.3 \mathrm{~m}^{2}\right.$, and $\left.21.3 \mathrm{~m}^{2}\right)$; mining height varies greatly with coal thickness, ranging from 2 to $6 \mathrm{~m}$; the working face is long and varies greatly $(201 \mathrm{~m}$, $300 \mathrm{~m}$, and $324 \mathrm{~m}$ ); the length of the anchor cable support $(6.3 \mathrm{~m}$ and $9.2 \mathrm{~m})$ is also different. Under this commonness and difference, the phenomenon of large deformation and strong failure of surrounding rock in 13-1 coal mining roadway is common.

As shown in Figure 3, in the deep mining roadway, the failure of the top-angle bolt support, fracturing instability of the sidewall signal column, and serious shrinkage of the roadway section due to the excessive mine pressure are common, which have an extremely adverse impact on the stability of the roadway and the safety of coal mining and tunneling activities. The influence of mining depth, mining height, face length, and support length on the stability of the surrounding rock of the mining roadway is systematically and completely analyzed in [23]. This paper mainly analyzes the deformation and failure process of the hard main roof of the deep mining roadway. Through FLAC3D postprocessing analysis, the vertical stress distribution of the 13-1 coal hard main roof with a face length of $250 \mathrm{~m}$, a mining height of $4 \mathrm{~m}$, a buried depth of $900 \mathrm{~m}$, and $7.3 \mathrm{~m}$ anchor cable support is shown in Figure 4.

It can be seen from Figure 4 that, during the mining of the working face, different areas of the roof of the front mining roadway are affected by the advance support pressure and lateral support pressure differently, which are manifested in that the peak stress of the main roof of the roadway near the working face is larger than that of the solid coal side. Further data processing and analysis can be obtained in which the support pressure of the main roof tends to reach the peak at $7 \mathrm{~m}$ in front of the working face. At this time, the solid coal side is $7 \mathrm{~m}$ away from the roadway side. The vertical stress at $9 \mathrm{~m}$ from the side of the working face to the roadway side reaches the peak, which is $24.8 \mathrm{MPa}$ and 26.6 MPa, respectively. The concentration factors estimated according to the equivalent original rock stress at $900 \mathrm{~m}$ buried depth are 1.10 and 1.18 , respectively, which provide important support for the boundary establishment of subsequent theoretical models.

\section{Theoretical Model Establishment and Analysis}

According to the test results of the surrounding rock of mechanical parameters, the main roof of 13-1 mining is hard, and the uniaxial compressive strength is about $120 \mathrm{MPa}$. Its stability will be the key to the overall stability of the surrounding rock of the mining roadway. For quantitative analysis, the conditions of model analysis are assumed as follows: (1) each rock stratum is a homogeneous, continuous, and isotropic material; (2) it is assumed that the surrounding rock in the elastic area of the mining roadway is the Winkler elastic foundation beam [24-26], which can provide a support reaction force of the same magnitude as the bearing pressure; (3) the bearing capacity of the plastic zone decreases sharply with the material damage of 13-1 mining and the immediate roof, and the damage function $d$ follows Weibull distribution; that is, the support reaction from the mining wall to the elastic-plastic junction increases gradually, but it is less than the bearing pressure of the main roof; (4) assuming that the main roof acts on the immediate roof and 13-1 mining in the form of given deformation, the surrounding rock deformation of the immediate roof and 13-1 mining around the roadway is consistent; (5) with the increase of bearing pressure, the radius of the plastic zone within the peak value of bearing pressure expands faster than the peak value of bearing pressure. It is assumed that it is in the same position, and the resultant force of the support reaction force and roof pressure after damage at the peak point are constant; (6) the main roof of 13-1 mining has high strength. When its thickness collapse ratio is less than $1 / 5$, it meets the requirements of the "beam" model. The key to the stability control of the surrounding rock under the hard 


\begin{tabular}{|c|c|c|c|c|}
\hline Layer & $\begin{array}{l}\text { Rock } \\
\text { name }\end{array}$ & \begin{tabular}{|c|} 
Thickness \\
$(\mathrm{m})$
\end{tabular} & $\begin{array}{c}\text { Histo- } \\
\text { gram }\end{array}$ & Lithology description \\
\hline Main roof & $\begin{array}{c}\text { Sandy } \\
\text { mudstone }\end{array}$ & $\begin{array}{c}2.5 \sim 3.1 \\
2.7 \\
\end{array}$ & 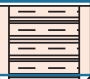 & Light gray, dense, massive, flat fracture \\
\hline \multirow{3}{*}{$\begin{array}{l}\text { Immediate } \\
\text { roof }\end{array}$} & Mudstone & \begin{tabular}{c|}
$2.6 \sim 3.5$ \\
2.9 \\
\end{tabular} & & Gray, dense, massive, locally transformed into fine sandstone \\
\hline & 13-2 coal & \begin{tabular}{|c|}
$0.5 \sim 1.4$ \\
0.8 \\
\end{tabular} & & Black, banded, broken \\
\hline & $\begin{array}{c}\text { Sandy } \\
\text { mudstone }\end{array}$ & \begin{tabular}{|c|}
$0.5 \sim 8.69$ \\
2.7 \\
\end{tabular} & \multirow{3}{*}{ 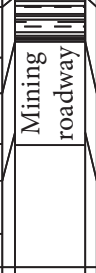 } & $\begin{array}{l}\text { Gray, dark gray, argillaceous structure, fracture development, } \\
\text { local phase transformation into fine sandstone }\end{array}$ \\
\hline Coal seam & $13-1$ coal & \begin{tabular}{|c|}
$2.37 \sim 3.75$ \\
2.88 \\
\end{tabular} & & $\begin{array}{l}\text { Black, massive, with a small amount of } \\
\text { powder in the middle, brittle }\end{array}$ \\
\hline $\begin{array}{l}\text { Immediate } \\
\text { floor }\end{array}$ & Mudstone & \begin{tabular}{|c|}
$3.57 \sim 4.85$ \\
4.15 \\
\end{tabular} & & Gray, dense, massive, brittle, flat fracture \\
\hline Main floor & Silt stone & \begin{tabular}{c|}
$2.55 \sim 3.7$ \\
3.05
\end{tabular} & & Gray, dark gray, dense, hard, siliceous and calcareous cementation \\
\hline
\end{tabular}

(a)

\begin{tabular}{|c|c|c|c|c|c|}
\hline Horizon & \begin{tabular}{|c|} 
Rock \\
stratum \\
columnar \\
$(1: 200)$
\end{tabular} & $\begin{array}{l}\text { Layer } \\
\text { thickness } \\
(\mathrm{m})\end{array}$ & $\begin{array}{l}\text { Accumulated } \\
\text { thickness }(\mathrm{m})\end{array}$ & Rock name & Lithology description \\
\hline $\begin{array}{l}\text { Main roof } \\
\text { Immediate }\end{array}$ & & 2.99 & 4.21 & Fine sandstone & $\begin{array}{l}\text { Light gray, grayish white, mainly composed of quartz, a small amount of siderite and } \\
\text { other dark substances, siliceous cementation, siderite and argillaceous lineation and band } \\
\text { composition, clear horizontal bedding, and local vertical fractures are developed }\end{array}$ \\
\hline \multirow[b]{2}{*}{ 13-1 coal } & \begin{tabular}{|l|l|}
--- & \\
\end{tabular} & 1.22 & 1.22 & Mudstone & Gray, dense, brittle, Sandy and rough \\
\hline & & $\begin{array}{l}0.65 \\
0.38 \\
4.11\end{array}$ & 0 & $13-1$ coal & \multirow[t]{2}{*}{$\begin{array}{l}\text { Black is mainly massive and flaky, with a small amount of granular, composed of } \\
\text { bright coal and dark coal, intercalated with vitrinite strip and weak glass luster. It } \\
\text { belongs to semi dark and semi bright briquette. A stable layer of gangue is developed } \\
\text { about } 0.6 \mathrm{~m} \text { below the roof, and partially developed at the bottom. The lithology of } \\
\text { gangue is mostly carbonaceous mudstone and locally mudstone }\end{array}$} \\
\hline \multirow{2}{*}{$\begin{array}{l}\text { Immediate } \\
\text { floor }\end{array}$} & -- & & & & \\
\hline & \begin{tabular}{|l|l|}
--1 \\
--1 \\
\end{tabular} & \multirow[t]{2}{*}{9.29} & \multirow[t]{2}{*}{9.29} & \multirow[t]{2}{*}{ Mudstone } & \multirow[t]{2}{*}{$\begin{array}{l}\text { Dark gray, gray, containing fossil fragments of plant roots, dark gray at the top } \\
\text { of } 1.00 \mathrm{~m} \text {, containing more carbonaceous matter and siderite nodules locally }\end{array}$} \\
\hline \multirow{2}{*}{ Main roof } & - & & & & \\
\hline & & 1.79 & 11.08 & Sandy mudstone & Gray, containing siderite nodules, rich in oblique feather and other plant fossil fragments \\
\hline Roof & & 2.32 & 13.40 & Siltstone & Light gray, gray, containing Muscovite fragments and more siderite nodules \\
\hline
\end{tabular}

(b)

\begin{tabular}{|c|c|c|c|c|c|}
\hline Horizon & Lithology & $\begin{array}{c}\text { Rock } \\
\text { stratum } \\
\text { columnar } \\
(1: 200)\end{array}$ & $\begin{array}{c}\text { Layer } \\
\text { thickness }\end{array}$ & $\begin{array}{l}\text { Cumulative } \\
\text { thickness }\end{array}$ & $\begin{array}{c}\text { Lithology } \\
\text { description }\end{array}$ \\
\hline Main roof & $\begin{array}{c}\text { Fine } \\
\text { sandstone }\end{array}$ & & $5 \mathrm{~m}$ & $8 \mathrm{~m}$ & $\begin{array}{l}\text { Bluish white mainly } \\
\text { composed of quartz } \\
\text { feldspar }\end{array}$ \\
\hline Immediate roof & Mudstone & & $3 \mathrm{~m}$ & $3 \mathrm{~m}$ & Cyan gray,dense,brittle \\
\hline 13-1 coal & 13-1 coal & & $\begin{array}{l}0.60 \\
(0.4) \\
3.50\end{array}$ & 0 & $\begin{array}{c}\text { Grayish black, } \\
\text { fragmentary,granular } \\
\text { and powdery, mainly } \\
\text { dark coal }\end{array}$ \\
\hline Immediate fioor & Mudstone & 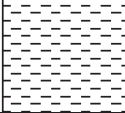 & $4 \mathrm{~m}$ & $4 \mathrm{~m}$ & $\begin{array}{l}\text { Gray, soft lithology, } \\
\text { uneven sediment } \\
\text { concentration }\end{array}$ \\
\hline
\end{tabular}

(c)

FIGURE 1: Comprehensive histogram of the 13-1 coal mining face in Huainan mining area. (a) 11413 working face. (b) 171301 working face. (c) 111303 working face. 


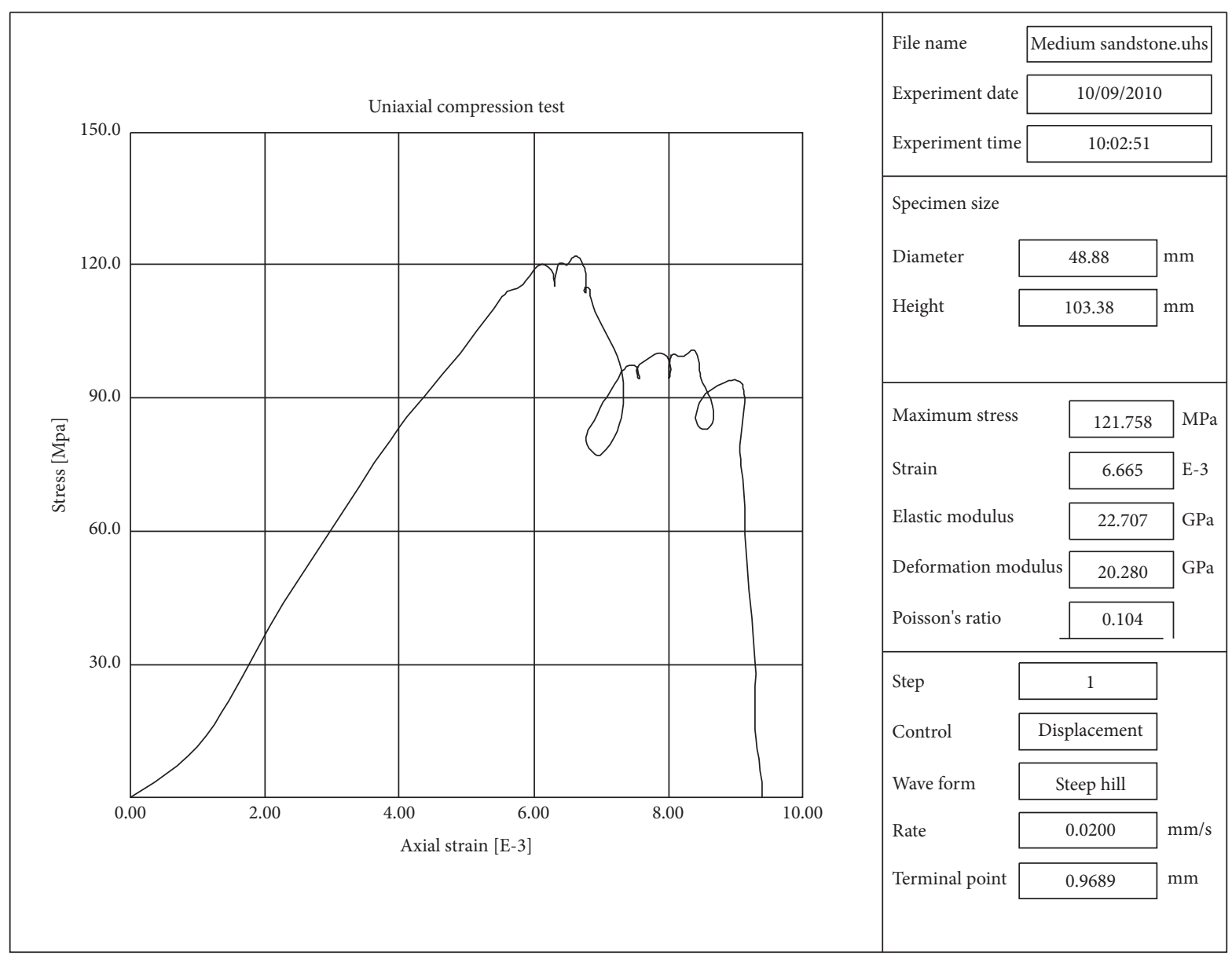

(a)

Figure 2: Continued. 


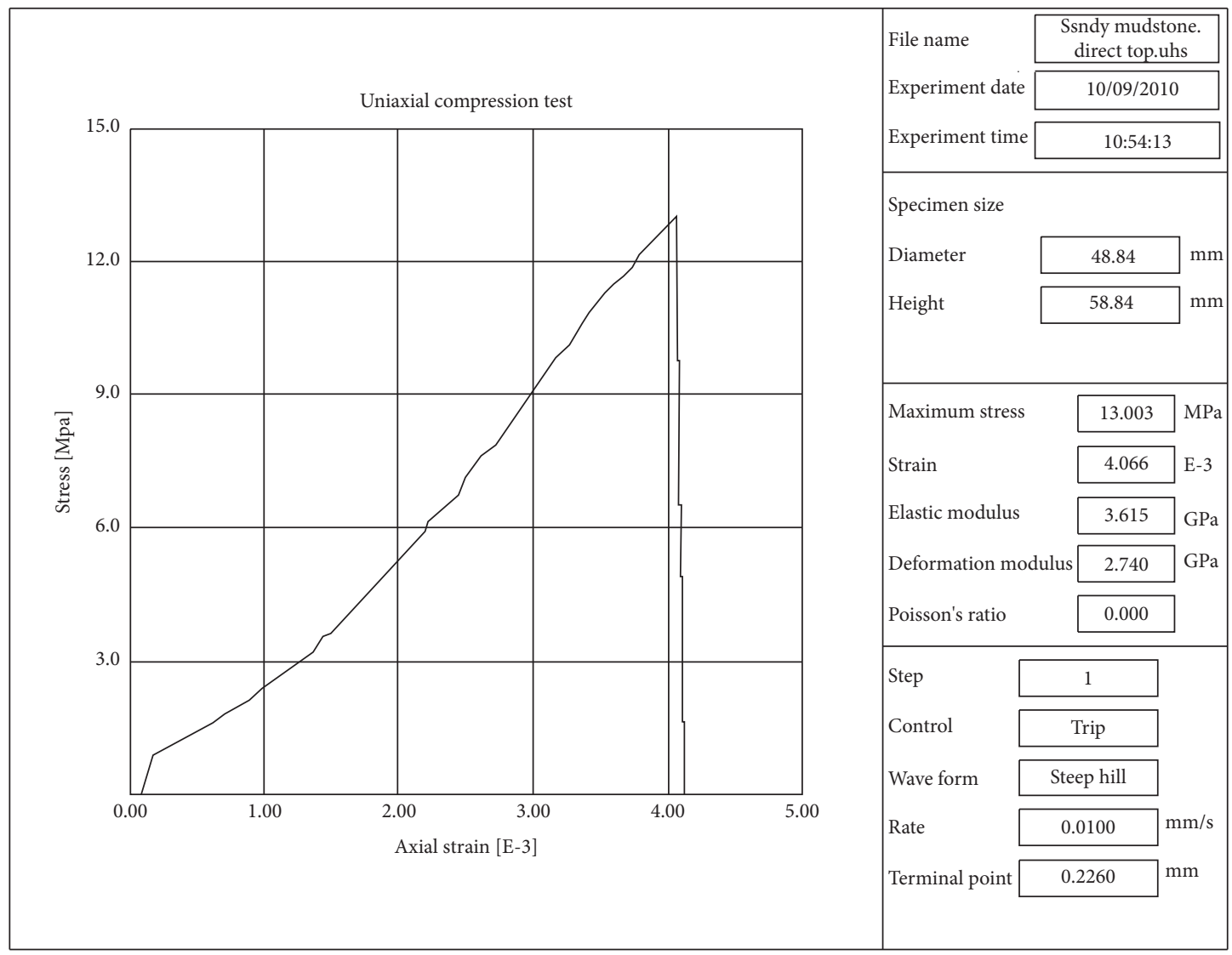

(b)

Figure 2: Test results of mechanical parameters of the hard main roof. (a) Uniaxial compression. (b) Brazilian splitting.

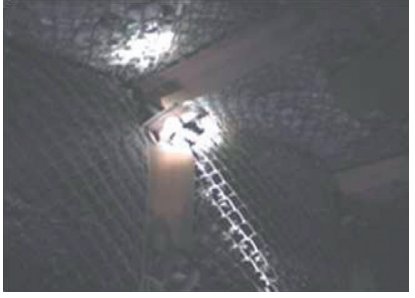

(a)

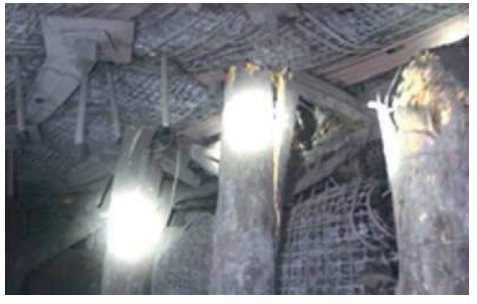

(b)

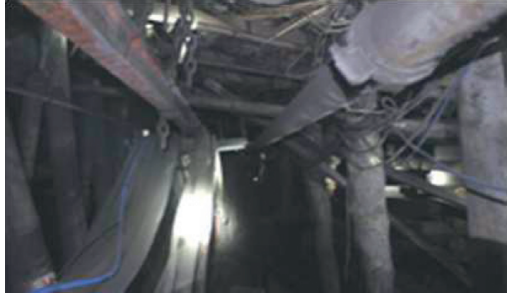

(c)

FIgURe 3: Actual photos of the strong strata behavior of the 13-1 coal mining roadway in Huainan mining area. (a) Failure of the top-angle bolt support. (b) Fracturing instability of the sidewall signal column. (c) Serious shrinkage of the roadway section.

main roof of the deep mining roadway is the stability control of the main roof rock beam during mining. The model test and numerical calculation results show that the roof movement of the deep hard main roof mining roadway during mining is different from that of the shallow mining roadway, and the deformation characteristics of shallow tensile strain and deep compressive strain appear. With the continuous increase of bearing pressure, the roof of the mining roadway is mainly damaged by tensile strain.

Build the stress analysis model of the main roof of the deep hard main roof mining roadway, as shown in Figure 5, analyze the deformation mechanism of the tension compression composite deformation of the surrounding rock inof the hard main roof of the deep hard main roof mining roadway, and put forward the corresponding prevention and control technology.

From the analysis of numerical simulation results, it can be seen that, during the mining of the working face, the bearing pressure distribution of the main roof above the front mining roadway is asymmetric, and its values are $K_{1}$ (mining side) and $K_{2}$ (solid side) $\left(K_{1}>K_{2}\right)$. From the analysis in the previous section, it can be seen that the plastic failure of the coal side of the deep hard roof mining roadway has zoning characteristics, and its bearing capacity is greatly reduced in the residual area, compared with the deep buried high stress; the support reaction can be ignored. It is 


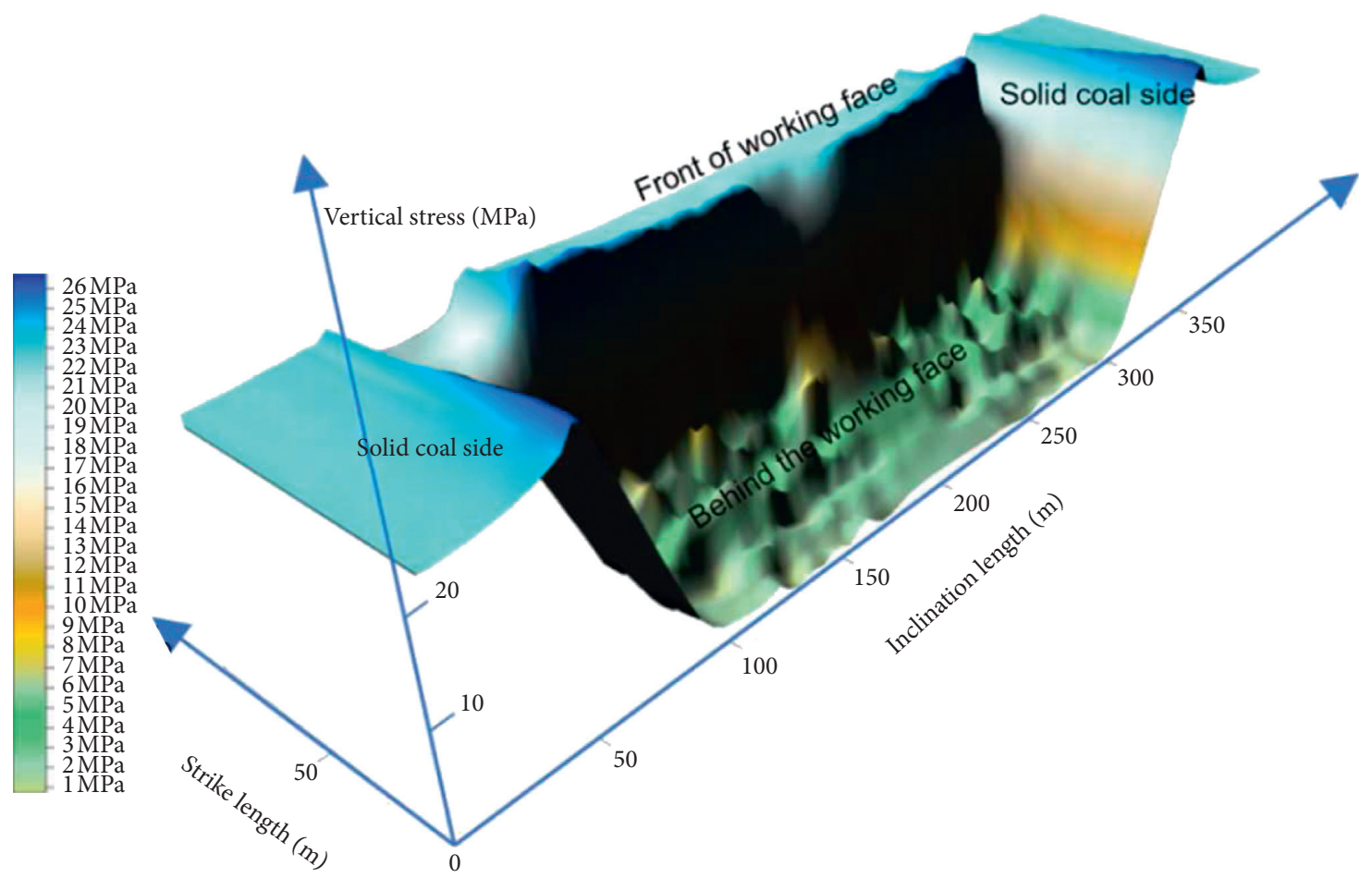

FIgURe 4: Distribution of vertical stress on the main roof on the 13-1 coal seam during working face mining.

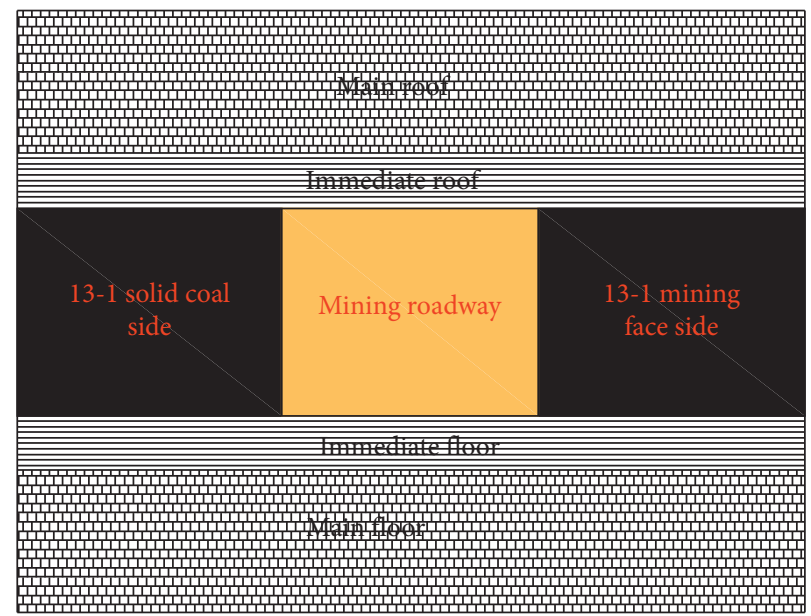

(a)

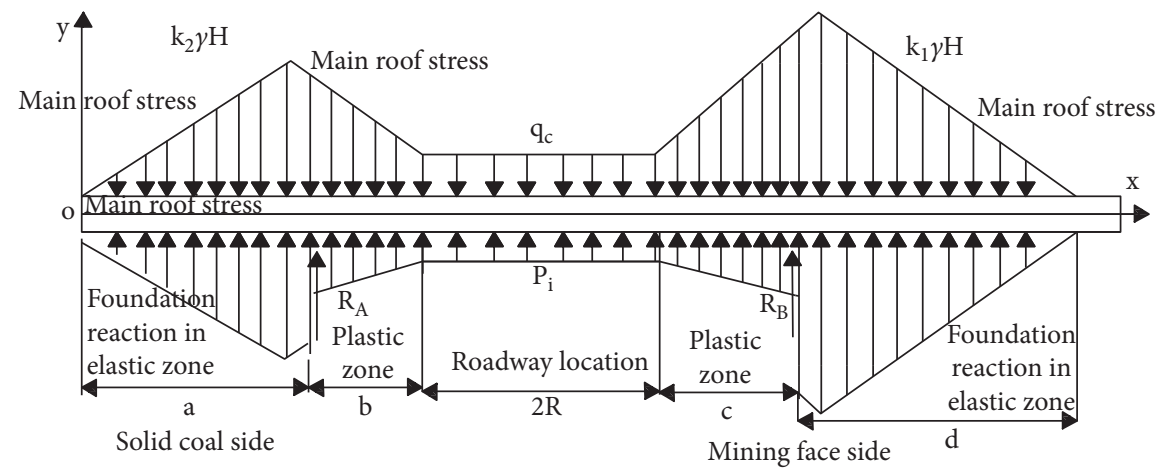

(b)

FIGURE 5: Stress analysis model of the hard main roof of the deep mining roadway. (a) Overall model of the mining roadway. (b) Stress analysis of the main roof in the mining roadway. 
proposed to consider that the main roof of the roadway in this area is in a free state, the elastic zone and softening zone are the main load-bearing body, and its junction is located within the roadway side from the peak point of the support pressure. The support pressure of the main roof beyond the peak point of the simplified support pressure is balanced by the roadway side reaction of the elastic zone, and its junction is simply supported; the pressure within the peak point acts on the main roof of the plastic zone (softening zone and residual zone). Let the damage factor of this zone be $D$ [24], and take the microelement as the following assumptions: (1) the deformation and failure of the microelement obey Hooke's law; that is, it satisfies the formula; (2) the microelement strength meets the statistical Weibull distribution, and the probability density function is as follows:

$$
\begin{gathered}
\sigma=E(1-D) \mathcal{E}, \\
f(x)=\frac{m}{a} x^{m-1} e^{-\left(x^{m} / \alpha\right)} .
\end{gathered}
$$

It can be seen from the analysis of [25] that

$$
D=1-e^{-\left(x^{m} / \alpha\right)} \text {. }
$$

Then, support reaction residual strength of the surrounding rock in this section is

$$
\sigma_{s}=E \varepsilon e^{-\left(x^{m} / \alpha\right)}=E \frac{y}{h} e^{-\left(x^{m} / \alpha\right)},
$$

where $m$ is the shape parameter and $n$ is the scale parameter.

$$
\left\{\begin{aligned}
& \sigma_{s}=E \varepsilon e^{-\left(x^{m} / \alpha\right)}=E \frac{y}{h} e^{-\left(x^{m} / \alpha\right)}, 0 \leq x \leq b, \\
& \sigma_{s}=E \varepsilon e^{-\left(x^{m} / \alpha\right)}=E \frac{y}{h} e^{-\left([x-(b+2 R+c)]^{m} / \alpha\right)}, \\
& b+2 R \leq x \leq b+2 R+c .
\end{aligned}\right.
$$

$$
\left\{\begin{array}{l}
q \frac{(b+2 R+c)^{2}}{2}+\frac{\left(\sigma_{s t}-q\right)}{2} b\left(2 R+c+\frac{2}{3} b\right)+\frac{\left(\sigma_{h c}-q\right) c}{2} \cdot \frac{c}{3}-R_{A}(b+2 R+c)=0, \\
R_{B}=q(b+2 R+c)+\frac{\left(\sigma_{s t}-q\right)}{2} b+\frac{\left(\sigma_{h c}-q\right)}{2} c-R_{A} .
\end{array}\right.
$$

Seek

$$
\left\{\begin{array}{l}
R_{A}=\frac{q(b+2 R+c)^{2} / 2+\left(\sigma_{s t}-q\right) / 2 b(2 R+c+2 / 3 b)+\left(\sigma_{h c}-q\right) c / 2 \cdot c / 3}{b+2 R+c}, \\
R_{B}=q(b+2 R+c)+\frac{\left(\sigma_{s t}-q\right)}{2} b+\frac{\left(\sigma_{h c}-q\right)}{2} c-\frac{q(b+2 R+c)^{2} / 2+\left(\sigma_{s t}-q\right) / 2 b(2 R+c+2 / 3 b)+\left(\sigma_{h c}-q\right) c / 2 \cdot c / 3}{b+2 R+c} .
\end{array}\right.
$$




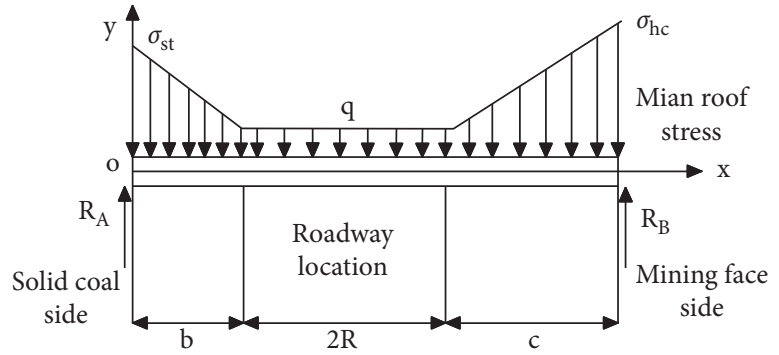

FiguRE 6: Simplified stress analysis model of the hard main roof in the deep mining roadway.

According to this, the bending moment of the main roof can be calculated and expressed in sections as follows:

$$
\begin{cases}M_{1}=\left(\sigma_{s t}-\frac{\sigma_{s t}-q}{b} x\right) x \cdot \frac{x}{2}+\frac{\sigma_{s t}-q}{b} x \cdot \frac{x}{2} \cdot \frac{2 x}{3}-R_{A}, & 0<x \leq b, \\ M_{2}=q x \cdot \frac{x}{2}+\left(\sigma_{s t}-q\right) \cdot \frac{b}{2}\left(x-\frac{b}{3}\right)-R_{A} x, & b \leq x \leq b+2 R, \\ M_{3}=q x \cdot \frac{x}{2}+\left(\sigma_{s t}-q\right) \cdot \frac{b}{2}\left(x-\frac{b}{3}\right)+\frac{\left(\sigma_{h c}-q\right)}{6 c}(x-b-2 R)^{3}-R_{A} x, & b+2 R \leq x \leq b+2 R+c .\end{cases}
$$

Angle of integration is

$$
\left\{\begin{array}{l}
E I \theta_{1}=\frac{\sigma_{s t} x^{3}}{6}-\frac{\left(\sigma_{s t}-q\right) x^{4}}{8 b}+\frac{\left(\sigma_{s t}-q\right) x^{4}}{12 b}-\frac{R_{A}}{2} x^{2}+B_{1}, \\
E I \theta_{2}=\frac{q x^{3}}{6}+\frac{\left(\sigma_{s t}-q\right) b(x-b / 3)^{2}}{4}-\frac{R_{A}}{2} x^{2}+B_{2}, \\
E I \theta_{3}=\frac{q x^{3}}{6}+\frac{\left(\sigma_{s t}-q\right) b(x-b / 3)^{2}}{4}+\frac{\left(\sigma_{h c}-q\right)(x-b-2 R)^{4}}{24 c}-\frac{R_{A}}{2} x^{2}+B_{3} .
\end{array}\right.
$$

Integral quadratic deflection is

$$
\left\{\begin{array}{l}
E I y_{1}=\frac{\sigma_{s t} x^{4}}{24}-\frac{\left(\sigma_{s t}-q\right) x^{5}}{40 b}+\frac{\left(\sigma_{s t}-q\right) x^{5}}{60 b}-\frac{R_{A}}{6} x^{3}+B_{1} x+C_{1}, \\
E I y_{2}=\frac{q x^{4}}{24}+\frac{b\left(\sigma_{s t}-q\right)(x-b / 3)^{3}}{12}-\frac{R_{A}}{6} x^{3}+B_{2} x+C_{2}, \\
E I y_{3}=\frac{q x^{4}}{24}+\frac{b\left(\sigma_{s t}-q\right)(x-b / 3)^{3}}{12}+\frac{\left(\sigma_{h c}-q\right)(x-b-2 R)^{5}}{120 c}-\frac{R_{A}}{6} x^{3}+B_{3} x+C_{3} .
\end{array}\right.
$$

The following assumptions are made, ignoring the initial subsidence of the main roof in the elastic zone, and it is considered that the subsidence of the main roof at the elastic-plastic junction is 0 . Substitute boundary conditions $\left.y\right|_{x=0}=0$ and $\left.y\right|_{x=b+2 R+c}=0$ and continuous condition $\left.\theta\right|_{x=b+}=\left.\theta\right|_{x=b-}, \quad y_{x=(b+2 R)+}=y_{x=(b+2 R)-},\left.\quad \theta\right|_{x=(b+2 R)+}=$ $\left.\theta\right|_{x=(b+2 R)-}$, and $y_{x=(b+2 R)+}=y_{x=(b+2 R)-}$. The undetermined parameters are calculated, and the results are as follows: 


$$
\begin{aligned}
& \left\{\begin{array}{l}
C_{1}=0 \\
C_{2}=-\frac{17}{3240} \sigma_{s t} b^{4}+\frac{17}{3240} q b^{4} \\
C_{3}=-\frac{17}{3240} \sigma_{s t} b^{4}+\frac{17}{3240} q b^{4}
\end{array}\right. \\
& B_{1}=\frac{1}{b+2 R+c}\left(\begin{array}{c}
-\frac{1}{3} q R^{2} b^{2}-\frac{1}{24} q b^{3} c-\frac{4}{3} q R^{3} c-\frac{2}{3} q R^{3} b-\frac{1}{12} q b^{2} c^{2}-\frac{1}{3} q R c^{3} \\
-\frac{1}{12} q R b^{3}-\frac{1}{12} q b c^{3}-q R^{2} c^{2}+R_{A} R b^{2}+\frac{1}{2} q R_{A} b^{2} c+2 R_{A} R^{2} b \\
+\frac{1}{2} R_{A} b c^{2}+2 R_{A} R^{2} c+R_{A} R c^{2}+\frac{1}{120} q b c^{4}-\frac{1}{3} q R b^{2} c-q R^{2} b c \\
-\frac{1}{2} q R b c^{2}+2 R_{A} R b c+\frac{1}{6} R_{A} b^{3}-\frac{1}{24} q c^{4}-\frac{2}{3} q R^{4}-\frac{1}{120} q b^{4} \\
+\frac{4}{3} R_{A} R^{3}+\frac{1}{6} R_{A} c^{3}-\frac{2}{3} R b^{2} c \sigma_{s t}-R^{2} b c \sigma_{s t}-\frac{1}{2} R b c^{2} \sigma_{s t}-\frac{1}{30} b^{4} \sigma_{s t} \\
-\frac{1}{8} b^{3} c \sigma_{s t}-\frac{1}{4} R b^{3} \sigma_{s t}-\frac{2}{3} R^{2} b^{2} \sigma_{s t}-\frac{1}{8} b^{3} c \sigma_{s t}-\frac{1}{4} R b^{3} \sigma_{s t} \\
-\frac{2}{3} R^{2} b^{2} \sigma_{s t}-\frac{1}{6} b^{2} c^{2} \sigma_{s t}-\frac{2}{3} R^{3} b \sigma_{s t}-\frac{1}{12} b c^{3} \sigma_{s t}-\frac{1}{120} b c^{4} \sigma_{h c}
\end{array}\right), \\
& B_{2}=\frac{1}{b+2 R+c}\left(\begin{array}{c}
-\frac{1}{3} q R^{2} b^{2}-\frac{1}{18} q b^{3} c-\frac{4}{3} q R^{3} c-\frac{2}{3} q R^{3} b-\frac{1}{12} q b^{2} c^{2}-\frac{1}{3} q R c^{3} \\
-\frac{1}{9} q R b^{3}-\frac{1}{12} q b c^{3}-q R^{2} c^{2}+R_{A} R b^{2}+\frac{1}{2} R_{A} b^{2} c+2 R_{A} R^{2} b \\
+\frac{1}{2} R_{A} b c^{2}+2 R_{A} R^{2} c+R_{A} R c^{2}+\frac{1}{120} q b c^{4}-\frac{1}{3} q R b^{2} c-q R^{2} b c \\
-\frac{1}{2} q R b c^{2}+2 R_{A} R b c+\frac{1}{6} R_{A} b^{3}-\frac{1}{24} q c^{4}-\frac{2}{3} q R^{4}-\frac{1}{45} q b^{4} \\
4-\frac{1}{3} R_{A} R^{3}+\frac{1}{6} R_{A} c^{3}-\frac{2}{3} R b^{2} c \sigma_{s t}-R^{2} b c \sigma_{s t}-\frac{1}{2} R b c^{2} \sigma_{s t}-\frac{7}{360} b^{4} \sigma_{s t} \\
-\frac{2}{9} b^{3} c \sigma_{s t}-\frac{2}{9} R b^{3} \sigma_{s t}-\frac{2}{3} R^{2} b^{2} \sigma_{s t}-\frac{1}{6} b^{2} c^{2} \sigma_{s t}-\frac{2}{3} R^{3} b \sigma_{s t} \\
-\frac{1}{12} b c^{3} \sigma_{s t}-\frac{1}{120} b c^{4} \sigma_{h c}
\end{array}\right) .
\end{aligned}
$$


Referring to the numerical simulation results and combined with the geological engineering conditions of the deep mining roadway, the corresponding parameters are selected as follows: $H=900 \mathrm{~m}, \gamma=25 \mathrm{kN} / \mathrm{m}^{3}, \quad k_{2}=2.5$, $k_{1}=1.8, \quad b=7 \mathrm{~m}, \quad c=9 \mathrm{~m}, \quad R=2.5 \mathrm{~m}, \quad q_{\mathrm{c}}=0.7 \mathrm{mN} / \mathrm{m}$, $p_{i}=0.3 \mathrm{mN} / \mathrm{m}, E=22 \mathrm{GPa}$, and layer thickness $h_{i}=2.5 \mathrm{~m}$ (meet the condition that the ratio of "beam" thickness to length is less than $1 / 5$. In addition, to ensure the safety of the beam, the normal stress of the beam cannot exceed a certain limit; that is, the beam must also meet both the normal stress strength condition that is $\sigma_{\max }=M y_{\max } / I_{Z}=M / W_{Z}$ and the shear stress strength condition that is $\tau_{\max }=V_{\max } S_{Z \max }^{*} / I_{z} d \leq[\tau]$; it was calculated to meet the two conditions). The beam width is taken as the unit length $1 \mathrm{~m}, I=h^{3} / 12=1.3 \mathrm{~m}^{4}$, and it should be noted that, in equation (6), $\sigma_{s t}$ and $\sigma_{h c}$ cannot be simply equal to the peak value of bearing pressure. Considering that the damaged area still has large bearing capacity, it is simplified; $\sigma_{h c}=0.05 \gamma H, 0.15 \gamma H$, and $0.25 \gamma H ; \sigma_{\text {st }}=0.01 \gamma H, 0.10 \gamma H$, and $0.2 \gamma H$. The influence of the resultant force of two vertical stresses at the elastic-plastic junction on the deflection of the main roof is analyzed, as shown in Figure 7.

It can be seen from Figure 7 that, under the action of asymmetric mining abutment pressure, with the increase of the peak value of abutment pressure (with the comprehensive effects of buried depth, mining height, face length, change of the support body, and reduction of bearing capacity after damage), although the relative difference between the two sides of abutment pressure remains unchanged, the deflection of the hard main roof increases rapidly, and the maximum value has increased from $21 \mathrm{~mm}$ (when $\sigma_{h c}=0.05 \gamma \mathrm{H}$ and $\sigma_{s t}=0.01 \gamma H$ ) to $324 \mathrm{~mm}$ (when $\sigma_{h c}=0.15 \gamma \mathrm{H}$ and $\sigma_{s t}=0.11 \gamma \mathrm{H}$ ) and then to $627.6 \mathrm{~mm}$ (when $\sigma_{h c}=0.25 \gamma H$ and $\sigma_{s t}=0.21 \gamma H$ ). The calculation results show that the peak value and position of the main roof pressure not only affect the bending moment and deflection but also affect the position of the maximum bending moment, that is, the position of tensile fracture, fix the peak position, and increase the roof pressure, and the maximum value point tends to move inward to the working face side.

The tensile strength of the main roof of the deep hard roof mining roadway is assumed to be of compressive strength $1 / 10$, up to $12 \mathrm{MPa}$; according to the maximum tensile stress criterion, when the tensile stress meets the following formula, the main roof will break and become unstable.

$$
\sigma_{\max }=\frac{M_{\max }\left(h_{i} / 2\right)}{I_{Z}}>[\sigma] .
$$

The maximum bending moment without tensile failure is calculated as

$$
\begin{aligned}
& M_{\max } \leq[\sigma] \frac{h_{i}^{2}}{6}, \\
& M_{\max } \leq 12.5 \mathrm{MN} \cdot \mathrm{m} .
\end{aligned}
$$

Parameters to calculate the deflection are $\sigma_{h c}=0.15 \gamma H$ and $\sigma_{s t}=0.11 \gamma H$. By substituting bending moment expression (10), the sectional curve of the bending moment of the main roof above the mining roadway can be calculated, as shown in Figure 8.

It can be seen from Figure 8 that the maximum bending moment of the main roof is obtained at $x=15.1 \mathrm{~m}$, and the maximum bending moment is $209 \mathrm{MN} \cdot \mathrm{m}$. Except for the small bending moment at the elastic-plastic junction, the whole rock beam of the main roof is in the stage of tensile failure and instability. Therefore, the main roof above the roadway is unstable at this time.

\section{Stability Control Countermeasures}

It can be seen from the analysis in the previous section that when the deep hard roof mining roadway is clearly affected by the mining support pressure, the deformation of the surrounding rock of the roof intensifies. At this time, it is often necessary to provide the support reaction $R_{C}$ and $R_{D}$ at the side slope angle with advanced monomers or advanced self-moving support or wooden point columns to limit the roof subsidence of the slope angle and strengthen the simplified main roof stress model of the support section, as shown in Figure 9.

Assuming that the reinforced support of $R_{C}$ and $R_{D}$ can limit the top angle subsidence under ideal conditions, the coal slope stability of the main roof "beam" can be treated according to the simple support condition, which is a statically indeterminate problem. Remove the constraints here, and replace them with $R_{C}$ and $R_{D}$. The analysis is as follows:

$$
\left\{\begin{array}{l}
q \frac{(b+2 R+c)^{2}}{2}+\frac{\left(\sigma_{s t}-q\right)}{2} b\left(2 R+c+\frac{2}{3} b\right)+\frac{\left(\sigma_{h c}-q\right) c}{2} \cdot \frac{c}{3}-R_{A}(b+2 R+c)-R_{C}(2 R+c)-R_{D} c=0 \\
R_{B}=q(b+2 R+c)+\frac{\left(\sigma_{s t}-q\right)}{2} b+\frac{\left(\sigma_{h c}-q\right)}{2} c-R_{A}-R_{C}-R_{D}
\end{array}\right.
$$

Seek 


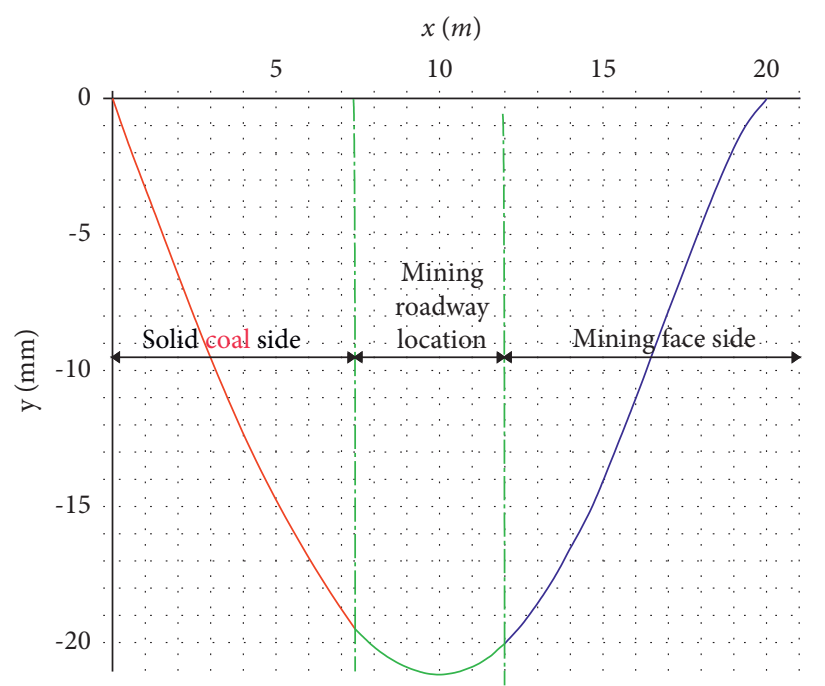

(a)

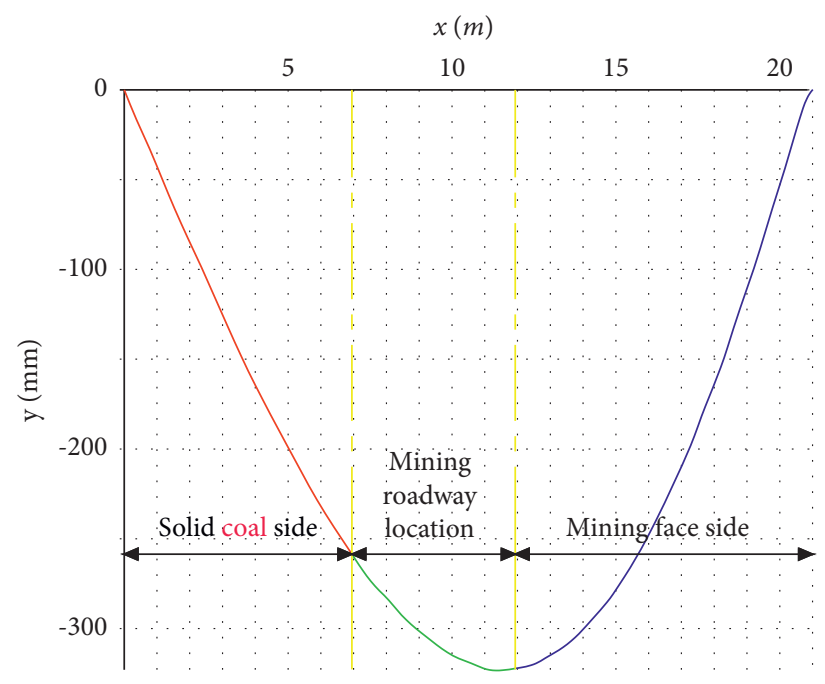

(b)

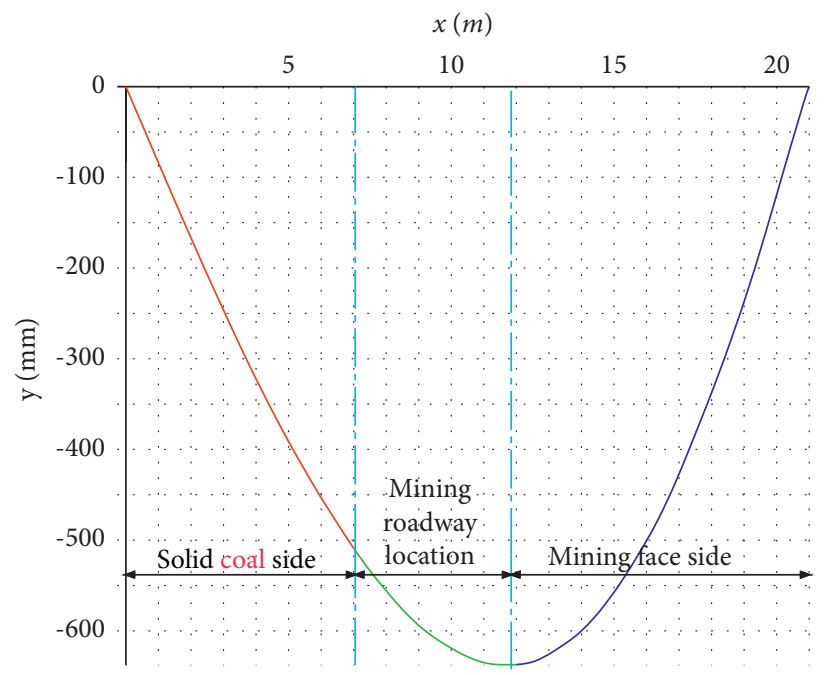

(c)

FIGURE 7: Deflection curve of hard main roof subsidence in the deep mining roadway (different pressures at the junction). (a) $\sigma_{h c}=0.05 \gamma H$; $\sigma_{s t}=0.01 \gamma \mathrm{H}$. (b) $\sigma_{h c}=0.15 \gamma \mathrm{H} ; \sigma_{s t}=0.11 \gamma \mathrm{H}$. (c) $\sigma_{h c}=0.25 \gamma \mathrm{H} ; \sigma_{s t}=0.21 \gamma \mathrm{H}$.

$$
\left\{\begin{array}{l}
R_{A}=\frac{q(b+2 R+c)^{2} / 2+\left(\sigma_{s t}-q\right) / 2 b(2 R+c+2 / 3 b)+\left(\sigma_{h c}-q\right) c / 2 \cdot c / 3-R_{C}(2 R+c)-R_{D} c}{b+2 R+c}, \\
R_{B}=q(b+2 R+c)+\left(\sigma_{s t}-q\right) / 2 b+\left(\sigma_{h c}-q\right) / 2 c \\
-\frac{q(b+2 R+c)^{2} / 2+\left(\sigma_{s t}-q\right) / 2 b(2 R+c+2 / 3 b)+\left(\sigma_{h c}-q\right) c / 2 \cdot c / 3-R_{C}(2 R+c)-R_{D} c}{b+2 R+c}-R_{C}-R_{D} .
\end{array}\right.
$$

According to this, the bending moment of the main roof can be calculated and expressed in sections as follows: 


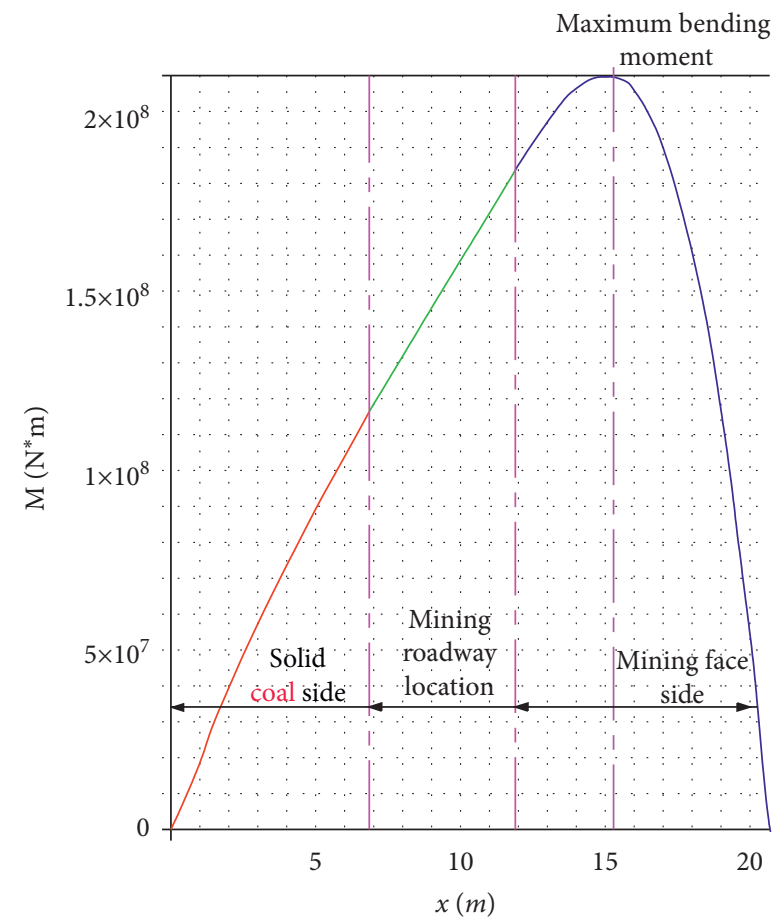

FIGURE 8: Bending moment curve of the hard main roof in the deep mining roadway.

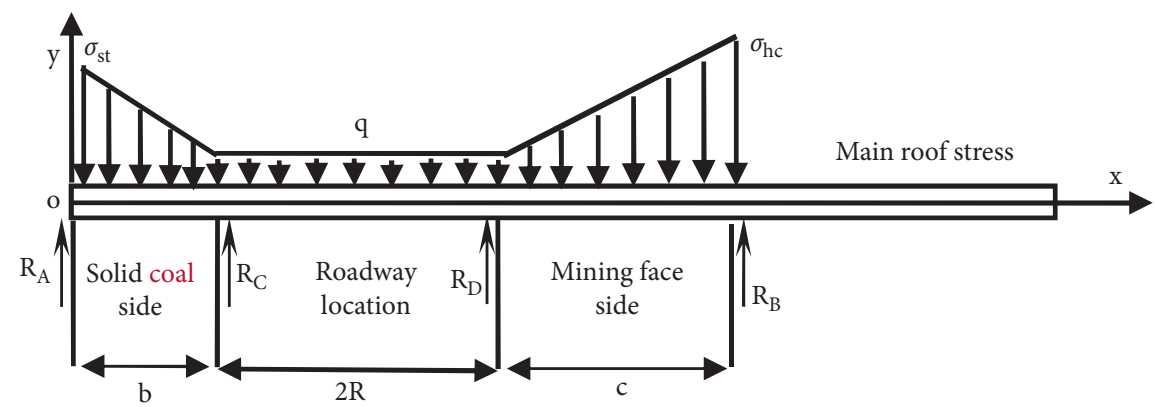

Figure 9: The simplified force analysis model of the main roof of deep typical gateways on the advanced support section.

$$
\begin{cases}M_{1}=\left(\sigma_{s t}-\frac{\sigma_{s t}-q}{b} x\right) x \cdot \frac{x}{2}+\frac{\sigma_{s t}-q}{b} x \cdot \frac{x}{2} \cdot \frac{2 x}{3}-R_{A} x, & 0<x \leq b, \\ M_{2}=q x \cdot \frac{x}{2}+\left(\sigma_{s t}-q\right) \cdot \frac{b}{2}\left(x-\frac{b}{3}\right)-R_{A} x-R_{C}(x-b), & b \leq x \leq b+2 R, \\ M_{3}=q x \cdot \frac{x}{2}+\left(\sigma_{s t}-q\right) \cdot \frac{b}{2}\left(x-\frac{b}{3}\right)+\frac{\left(\sigma_{h c}-q\right)}{6 c}(x-b-2 R)^{3}-R_{A} x-R_{C}(x-b)-R_{D}(x-b-2 R), & b+2 R \leq x \leq b+2 R+c .\end{cases}
$$


Angle of integration is

$$
\left\{\begin{array}{l}
E I \theta_{1}=\frac{\sigma_{s t} x^{3}}{6}-\frac{\left(\sigma_{s t}-q\right) x^{4}}{8 b}+\frac{\left(\sigma_{s t}-q\right) x^{4}}{12 b}-\frac{R_{A}}{2} x^{2}+B_{1}, \\
E I \theta_{2}=\frac{q x^{3}}{6}+\frac{\left(\sigma_{s t}-q\right) b(x-b / 3)^{2}}{4}-\frac{R_{A}}{2} x^{2}-\frac{R_{C}}{2}(x-b)^{2}+B_{2}, \\
E I \theta_{3}=\frac{q x^{3}}{6}+\frac{\left(\sigma_{s t}-q\right) b(x-b / 3)^{2}}{4}-\frac{R_{A}}{2} x^{2}-\frac{R_{C}}{2}(x-b)^{2}+\frac{\left(\sigma_{h c}-q\right)}{24 c}(x-b-2 R)^{4}-\frac{R_{D}}{2}(x-b-2 R)^{2}+B_{3} .
\end{array}\right.
$$

Integral quadratic deflection is

$$
\left\{\begin{array}{l}
E I y_{1}=\frac{\sigma_{s t} x^{4}}{24}-\frac{\left(\sigma_{s t}-q\right) x^{5}}{40 b}+\frac{\left(\sigma_{s t}-q\right) x^{5}}{60 b}-\frac{R_{A}}{6} x^{3}+B_{1} x+C_{1}, \\
E I y_{2}=\frac{q x^{4}}{24}+\frac{b\left(\sigma_{s t}-q\right)(x-b / 3)^{3}}{12}-\frac{R_{A}}{6} x^{3}-\frac{R_{C}}{6}(x-b)^{3}+B_{2} x+C_{2}, \\
E I y_{3}=\frac{q x^{4}}{24}+\frac{b\left(\sigma_{s t}-q\right)(x-b / 3)^{3}}{12}+\frac{\left(\sigma_{h c}-q\right)(x-b-2 R)^{5}}{120 c}-\frac{R_{A}}{6} x^{3}-\frac{R_{C}}{6}(x-b)^{3}-\frac{R_{D}}{6}(x-b-2 R)^{3}+B_{3} x+C_{3} .
\end{array}\right.
$$

Substitute boundary conditions $\left.y\right|_{x=0}=0,\left.y\right|_{x=b+2 R+c}=0$, $\left.y\right|_{x=b}=0$, and $\left.y\right|_{x=b+2 R}=0$ and continuous condition $\left.\theta\right|_{x=b+}=\left.\theta\right|_{x=b-}, \quad y_{x=(b+2 R)+}=y_{x=(b+2 R)-},\left.\quad \theta\right|_{x=(b+2 R)+}=$ $\left.\theta\right|_{x=(b+2 R)-}$, and $y_{x=(b+2 R)+}=y_{x=(b+2 R)-}$. Substitute relevant parameters: $H=900 \mathrm{~m}, \gamma=25 \mathrm{kN} / \mathrm{m}^{3}, k_{2}=2.5, k_{1}=1.8$, $b=7 \mathrm{~m}, c=9 \mathrm{~m}, R=2.5 \mathrm{~m}, q_{c}=0.7 \mathrm{mN} / \mathrm{m}, p_{i}=0.3 \mathrm{mN} / \mathrm{m}$, $E=22 \mathrm{GPa}$, and layer thickness $h_{i}=2.5 \mathrm{~m}$; draw the deflection curve of the hard main roof as shown in Figure 10.

The model explains the mechanism of compression rebound deformation of the hard roof slab in the deep roadway. If the anchor end of the anchor cable is installed at this position, according to the deformation characteristics of "easy to pull but not easy to press" of the rock, the surrounding rock of the roof in the compression section is stable. Therefore, the overall surrounding rock stability of the mining roadway will be effectively controlled, which provides theoretical guidance for the range and parameter design of the roof support. As shown in Figure 10, after strengthening the support of the deep mining roadway, the stability of the roadway is improved by reflecting the deflection curve of the main roof.

\section{Engineering Applications and Effects}

Based on the theoretical calculation of the model of the "simply supported beam," it can be seen that the timely support of the sidewall roof of the roadway and reducing the deflection displacement of the main roof can effectively reduce the roof subsidence. If the deformation is limited or the support force is sufficient, the roof will form a rebound compression zone. If the anchor end of the anchor cable support can be installed in the compression zone, the stability of the overall surrounding rock of the roadway will be effectively controlled. Based on this, the principle of "strong side protection on both sides of the roof" is put forward. The specific improvement measures are as follows: it is proposed to expand the roadway excavation section to $5 \mathrm{~m} \times 3.5 \mathrm{~m}$, large deformation is reserved at $3.5 \mathrm{~m}$, and self-moving support is implemented in the air return roadway of working face 1282 (3) of Dingji Coal Mine for timely advance support; in order to meet the needs of roof management of advanced self-moving support, the track inclined roadway and transportation inclined roadway in the 171303 working face of Liuzhuang Coal Mine are optimized from the initial straight wall semicircular arch section to the straight wall semicircular flat roof arch section; on the basis of the failure of mechanical air roadway support in the 111303 working face of Zidong Mine, two sides are added $\Phi 6.3 \mathrm{~m}$ anchor cable, the roof anchor cable is changed from $6.3 \mathrm{~m}$ to $7.3 \mathrm{~m}$, the straight wall arch roadway is adopted, the middle is followed by the excavation, and a row of wooden point columns with a diameter of $200 \mathrm{~mm}$ are erected head-on, which can not only reduce the span but also serve as signal columns. The above roof control measures greatly improve the support effect of the deep 13-1 coal mining roadway in Huainan mining area compared with the adjacent 1141 (3) working face, 171301 working face, and 111303 working face, as shown in Figures 11 and 12. 


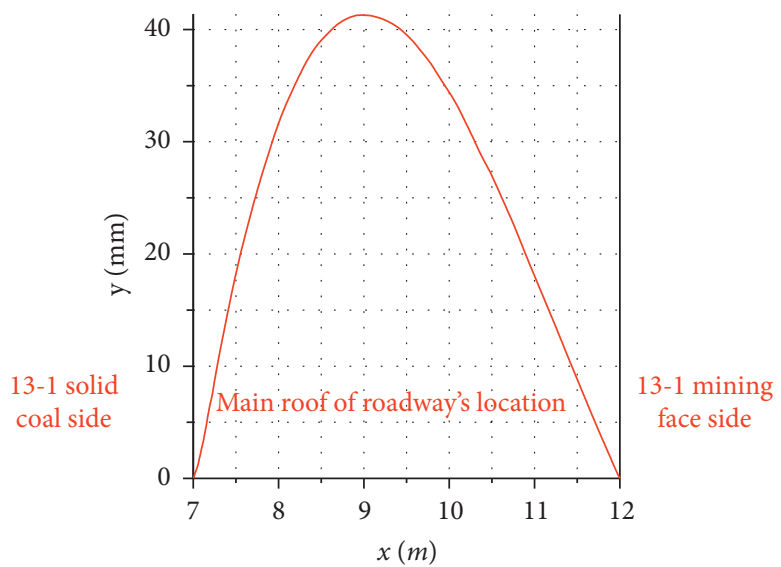

Figure 10: Deflection curve on the main roof of deep typical gateways after side and corner strengthening.

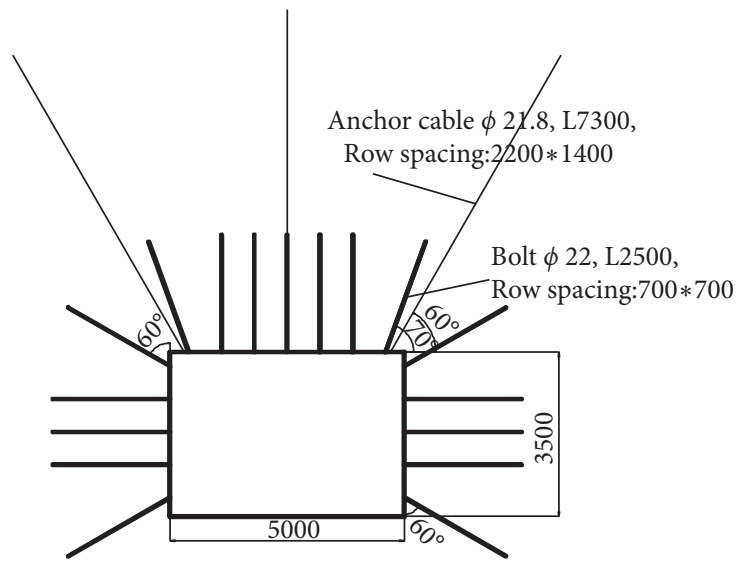

(a)

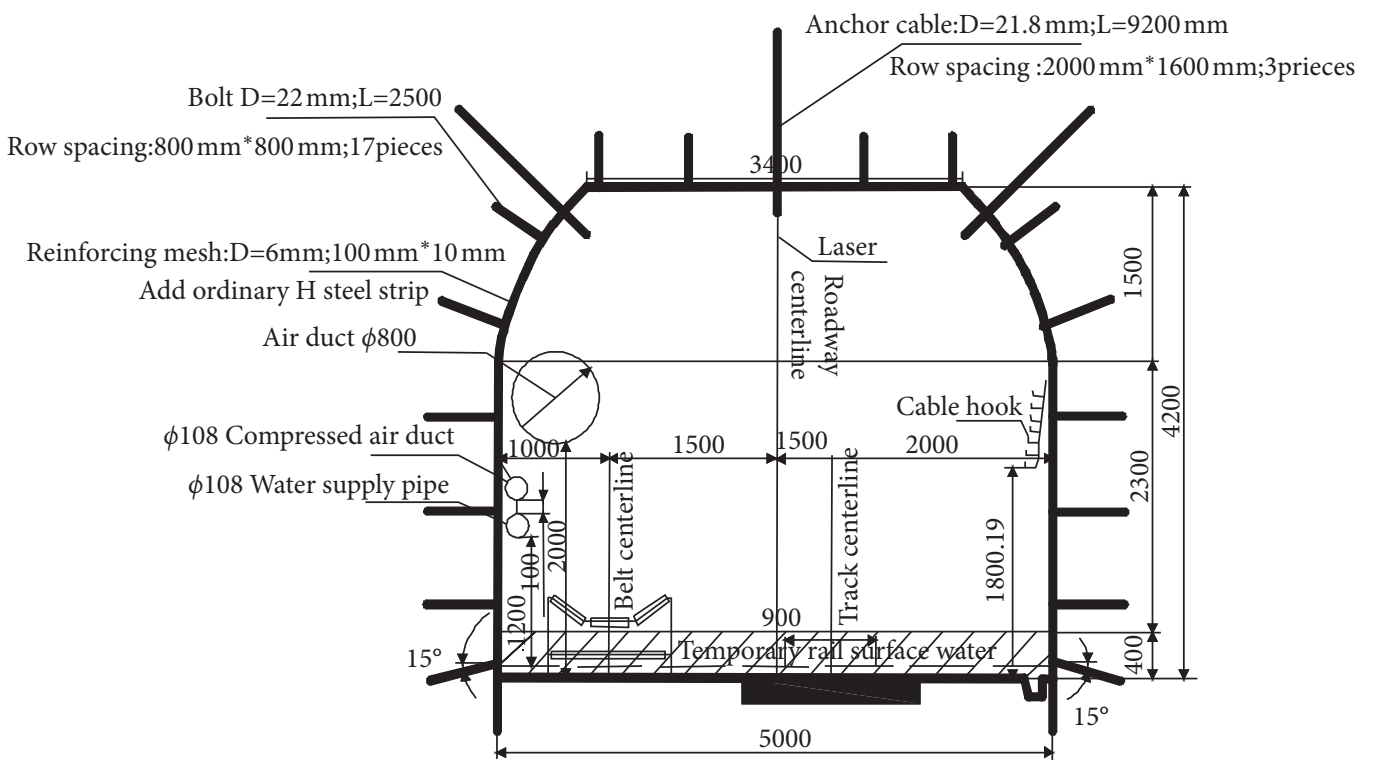

(b)

Figure 11: Continued. 


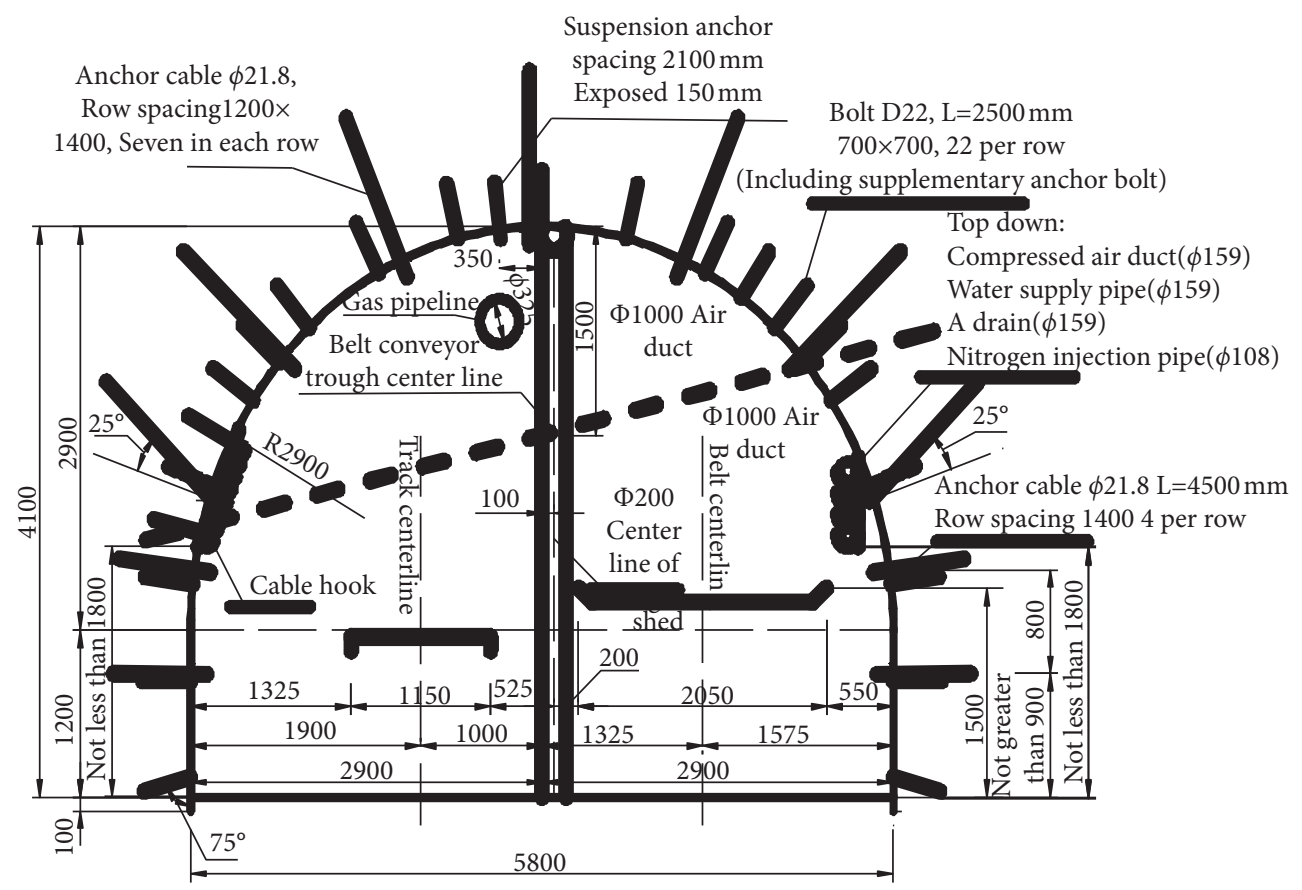

(c)

FIGURE 11: Strong wall and side roof support for the 13-1 coal seam roadway under the hard roof in Huainan mining area. (a) 1282 (3) basic support of the air return roadway in the working face. (b) 171303 basic support of the transportation roadway in the working face. (c) 111304 basic support of the transportation roadway in the working face.

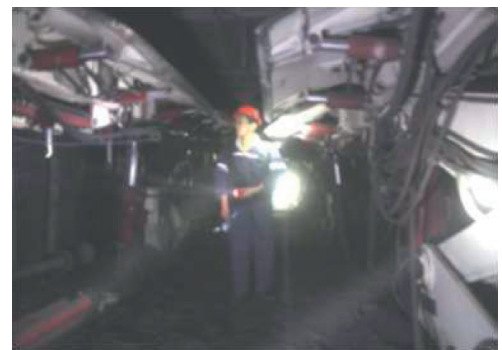

(a)

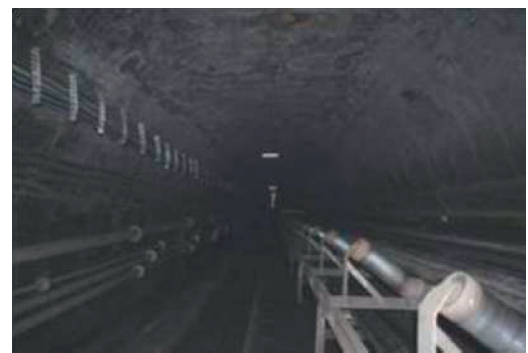

(b)

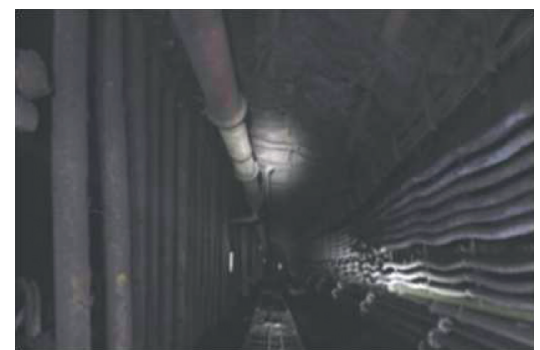

(c)

FIGURE 12: Improved support effect of the 13-1 coal roadway in Huainan mining area. (a) 1282 (3) strengthening roadway slope angle support with the self-moving support in the working face. (b) 171303 corner anchor cable reinforcement and support of the transportation roadway in the working face. (c) 111304 reinforcement and support of the machine roadway roof and side-angle anchor cable in the working face.

\section{Conclusions}

(1) Based on the mechanical parameters of the surrounding rock, the uniaxial compressive strength of the 13-1 coal main roof is $122 \mathrm{MPa}$, and the stress distribution law of the hard roof during mining is obtained by numerical simulation; a simply supported beam calculation model of the hard roof based on damage factor $D$, support reactions $R_{A}$ and $R_{B}$ in the elastic-plastic boundary area between the solid coal and mining face, and critical range $c(9 \mathrm{~m})$ and $b(7 \mathrm{~m})$ is constructed.
(2) Considering that the damaged area still has large bearing capacity, the vertical stresses at the elasticplastic junction of the stope side and solid coal side are calculated and analyzed as $k_{1} \gamma H(0.05 \gamma H, 0.15 \gamma H$, and $0.25 \gamma H)$ and $k_{2} \gamma H(0.01 \gamma H, 0.10 \gamma H$, and $0.2 \gamma H)$, respectively. The maximum deflection of roof subsidence is $21 \mathrm{~mm}, 324 \mathrm{~mm}$, and $627.6 \mathrm{~mm}$, respectively; the vertical peak pressure and its position of the hard main roof not only affect the bending moment and deflection but also affect the position where the maximum bending moment occurs, that is, the position where it can be broken, fix the peak 
position, and increase the main roof pressure, and the maximum point tends to move inward to the working face side.

(3) Furthermore, according to the tensile failure instability criterion, when $K_{1}=0.15$ and $K_{2}=0.10$, the maximum bending moment of the top beam is $209 \mathrm{mN} \cdot \mathrm{m}$ at the side of the working face $3.1 \mathrm{~m}$ away from the roadway slope, and the whole hard main roof is in tensile failure instability except for the small bending moment at the elastic-plastic junction.

(4) To prevent tensile failure and instability, it is proposed that, after the corner reinforcement reduces the roof displacement (or provides support reaction force), the stress deformation of the main roof rock beam is analyzed. According to the solution steps of the statically indeterminate beam, the support force and its deflection curve acting on the roof are obtained by using the method of releasing constraints, the phenomenon of roof rebound is found, and the possibility of roof compression deformation and compression zone is theoretically explained. This paper puts forward the "principle of strengthening the roof on both sides" and implements the advanced self-moving support and strengthens the roof angle support in the return air roadway of the 1282 (3) working face in Dingji Coal Mine, the track inclined roadway and transportation inclined roadway of the 171303 working face in Liuzhuang Coal Mine, and the machine air roadway of the 111303 working face in Kouzidong mine.

(5) Future research opportunities of this paper may focus on how to control the deflection of the hard main roof which increases rapidly due to the increase of the stress concentration factor of solid coal side $k_{1}$ and mining face side $k_{2}$, while the face mining period except the corner reinforcement reduces the roof displacement such as drilling holes to reduce stress concentration and transfer stress peak positions, and grouting is used to strengthen the surrounding rock near the shallow side of the working face under the action of high stress, improve the overall strength and bearing capacity of the surrounding rock, and realize the stability control of the hard roof of the roadway.

\section{Data Availability}

The data used in the field measurement can be obtained from the corresponding author upon request.

\section{Conflicts of Interest}

The authors declare no conflicts of interest.

\section{Authors' Contributions}

All authors contributed to this article. During the research, Xiaoyu Lu, Yongqiang Yuan, Chen $\mathrm{Li}$, and Chao Li reviewed and modified the manuscript.

\section{Acknowledgments}

The authors would like to thank their tutor Professor Hua Xinzhu for his guidance on this paper. The authors acknowledge the financial support provided by the Institute of Energy, Hefei Comprehensive National Science Center under Grant No. GXXT-2020-008 and the National Natural Science Foundation of China (Grant nos. 51974008 and 51774010).

\section{References}

[1] Y. S. Yang, Z. M. Fang, G. Y. Ji, B. G. Zhao, and S. J. Wei, "Study on Mechanical Properties and Control Technology of Surrounding Rock in the Fracture Zone of a Roadway," Shock and Vibration, vol. 2021, Article ID 6628593, 14 pages, 2021.

[2] Y. . Yuan, W. J. Wang, C. Yuan, and W. Yu, "Large deformation failure mechanism of surrounding rock for gateroad under dynamic pressure in deep coal mine," Journal of China Coal Society, vol. 25, no. 1, pp. 32-35, 2000.

[3] X. M. Sun, J. Yang, and W. F. Cao, "Research on space-time action rule of bolt-net-anchor coupling support for deep gateway," Chinese Journal of Rock Mechanics and Engineering, vol. 5, pp. 895-900, 2007.

[4] F. X. Jiang, "Application of thin plate mechanics solution in the hard roof of working face," Journal of Xi'an Mining Institute, vol. 2, pp. 12-19+28, 1991.

[5] Z. L. Mu, L. M. Dou, G. W. Zhang, S.-B. Zhang, and J. Zhang, "Study of prevention methods of rock burst disaster caused by hard rock roof," Journal of China University of Mining \& Technology, vol. 6, pp. 737-741, 2006.

[6] Z. G. Wu, M. H. Zhai, and T. Z. Zhou, "Prediction of roof pressure of the west mine in Xuzhou," Chinese Journal of Rock Mechanics and Engineering, vol. 15, no. 2, pp. 163-170, 1996.

[7] X. R. Wu and H. Q. Guo, "Forecast and prevention of rock burst in hard roof," Ground Pressure and Strata Control, vol. 3, pp. 211-214, 1999.

[8] F. L. Li, C. Wang, and C. S. Duan, "Using advanced deep hole preblasting to deal with hard roof," Ground Pressure and Strata Control, vol. 3, pp. 72-74, 2001.

[9] S. H. Yan, Y. Ning, L. J. Kang, Y. W. Shi, Y. G. Wang, and Y. F. Li, "The mechanism of hydro breakage to control hard roof and its test study," Journal of China Coal Society, vol. 25, no. 1, pp. 32-35, 2000.

[10] K. Wang, T. H. Kang, and H. T. Li, "Study of control caving methods and reasonable hang roof length on hard roof," Chinese Journal of Rock Mechanics and Engineering, vol. 15, no. 2, pp. 163-170, 1996.

[11] H. Jing, J. Wu, and Q. Yin, K. Wang, Deformation and failure characteristics of anchorage structure of surrounding rock in deep roadway," International Journal of Mining Science and Technology, vol. 30, no. 5, pp. 593-604, 2020.

[12] B. X. Huang, N. Zhang, H. W. Jing et al., "Large deformation theory of rheology and structural instability of the surrounding rock in deep mining roadway," Journal of China Coal Society, vol. 45, no. 3, pp. 911-926, 2020.

[13] C. J. Hou, "Effective approach and basic framework of surrounding rock control in deep roadway," Journal of China University of Mining \& Technology, vol. 46, no. 3, pp. 467-473, 2017.

[14] N. J. Ma, X. D. Zhao, Z. Q. Zhao, J. Li, and X. F. Guo, "Stability analysis and control technology of mine roadway roof in deep mining," Journal of China Coal Society, vol. 40, no. 10, pp. 2287-2295, 2015. 
[15] L. Yuan, J. H. Xue, Q. S. Liu, and B. Liu, "Surrounding rock stability control and support technique in deep rock roadway for coal mine," Journal of China Coal Society, vol. 36, no. 4, pp. 535-543, 2011.

[16] N. Zhang, C. Wang, M. S. Gao, and Y. M. Zhao, "Roadway support difficulty classification and controlling techniques for Huainan deep coal mining," Chinese Journal of Rock $\mathrm{Me}$ chanics and Engineering, vol. 28, no. 12, pp. 2421-2428, 2009.

[17] H. P. Kang, P. F. Jiang, B. X. Huang et al., "Roadway strata control technology by means of bolting-modification-destressing in synergy in $1000 \mathrm{~m}$ deep coal mines," Journal of China Coal Society, vol. 45, no. 3, pp. 845-864, 2020.

[18] J. B. Bai, X. Y. Wang, and Z. Yao, "Study of coupling support in soft rock roadway under high stress," Journal of China University of Mining \& Technology, vol. 26, no. 4, pp. 421-425, 2007.

[19] C. J. Hou, X. Y. Wang, J. B. Bai, N. K. Ming, and W. Wu, "Basic theory and technology study of stability control for surrounding rock in deep roadway," Journal of China University of Mining \& Technology, vol. 50, no. 1, pp. 1-12, 2021.

[20] C. J. Wu, T. Qin, L. Wang, and Z. Liu, "Research on surrounding rock control technology of dongbaowei deep mining roadway," Advances in Civil Engineering, vol. 2021, Article ID 6660989, 10 pages, 2021.

[21] J. F. Cui, W. J. Wang, J. Qian, G. Peng, H. Wu, and P. F. Wang, "Measurement and analysis of roadway deformation and stress under mining-induced stress," Shock and Vibration, vol. 2021, 2021.

[22] Z. Y. Jin, Y. Xu, T. Peng, and L. Gao, "Roof control technology of mining roadway under the influence of advanced supporting pressure," Advances in Civil Engineering, vol. 2021, Article ID 2049755, 8 pages, 2021.

[23] D. H. Chen, Research on Fractured Deformation Characteristics and Control Mechanism of Surrounding Rock in Deep Typical Gateways, Anhui University of Science and Technology, Huainan, China, 2014.

[24] D. Krajcinovic, "Distributed damage theory of beams in pure bending," Journal of Applied Mechanics, vol. 46, no. 3, pp. 592-596, 1979.

[25] K. G. Fan, Study on Damage-Failure Effect and Non-harmonious Control Mechanism of Weak Structure of Surrounding Rocks of Roadways, Shandong university of science and technology, Qingdao, China, 2003.

[26] J. Q. Jiang, Mining Pressure and Strata control, China University of mining and Technology Press, Xuzhou, China, 2007. 